\title{
Addressing a Lost Opportunity: Towards Science-Informed Land Use Planning
}

\author{
Darryl Low Choy
}

\section{Key Points}

- Post-World War II (WWII), Australia was a leader in the development of scientific information systems to support natural resource management including the assessment of a landscape's non-urban development potential.

- Surprisingly, there was little uptake of these environmental resource mapping initiatives into the land use planning sector, which deals with significant landscape modifications.

- Overlooking of this noteworthy development represented a major lost opportunity to better inform the decision-making process through a land use planning process that was based on reliable biophysical science.

- Alternative planning paradigms have subsequently emerged that address this lost opportunity and demonstrate the use of science to better inform the land use planning process.

- Holistic and environmentally based planning, with a strong nexus between land use planning and environmental sciences, will require a 'marriage' between planners and scientists. 


\section{Introduction}

Australia has led the way for many decades in the design and development of scientific information systems to support natural resource management. It was an early innovator in the use and application of aerial photography (principally vertical, but also oblique) for the purposes of landscape interpretation. However, there has been surprisingly little uptake of these systems and their content into the land use planning sector, in which most landscape-scale decisions that affect the environment and can lead to significant landscape modifications are made. Land use planning refers to various forms of statutory, but also non-statutory, planning. This is referred to in the literature under a variety of terms, such as town, city, spatial, physical or urban and regional planning. It is the planning that is undertaken by local government and certain state government agencies over freehold and crown lands for the purposes of defining the future location and scale of urban and rural settlements and land use activities.

The early environmental (landscape) resource mapping initiatives were never intended to be used to support land use planning endeavours; however, in situations in which they coincided geographically, they could have provided an excellent foundation upon which plans for the future development of our cities, especially the regions, might have been based. In other circumstances, their methodology could have been employed to better inform the planning process. The land use planning sector has an extremely poor track record of utilising these scientifically based information resources; disconnections between scientific information systems and regional-scale planning initiatives have dominated national and state government policy at significant times in Australia's development. This chapter provides an overview of selected major regional-scale Australian land use planning initiatives to identify their degree of nexus with parallel scientific information systems of similar scale and focus. Some consideration of the circumstances of these relationships and lessons for the future are offered by way of conclusion.

\section{Post-WWII Resource Mapping (1946-70s)}

WWII highlighted the paucity of adequate mapping across the continent, as well as the sparsely populated and unproductive nature of its northern regions. Rapid topographic mapping was commenced in 1942 utilising trimetrogon reconnaissance photography. By the end of the war, 
vertical aerial photography had become the major tool of cartographers. Number 87 Squadron of the Royal Australian Air Force was the principal vertical aerial photography agent for the national mapping effort until it was disbanded in 1953. This extensive and systematic vertical aerial photography effort led to a complete coverage of the Australian continent by the mid-1960s (with photos at nominal scales of 1:50,000 to 1:84,000). Overseen by the National Mapping Council, these strategic base mapping initiatives were coordinated by the National Mapping Office (from 1951), then the National Mapping Section, Property and Survey Branch, Department of Interior (later, the Division of National Mapping). These early national mapping initiatives left a rich legacy of one-inch to the mile and 1:250,000 topographic maps supported by continental coverage of black-and-white vertical aerial photographs (largely at approximately 40,000-feet flying height).

In the post-WWII era, the Australian, Queensland and Western Australian governments prioritised the need to undertake systematic surveys of the land resources and development potential of northern Australia. The Commonwealth Scientific and Industrial Research Organisation (CSIRO) was tasked to undertake a reconnaissance survey of the Katherine-Darwin area in 1946 that culminated in the publication of the first report in CSIRO's Land Research Series (Christian \& Stewart, 1952). By 1977, when the series ended, it had produced 39 reports across 36 regions, including 17 reports dealing with regions in Papua New Guinea. CSIRO's initiative required a new approach to integrating biophysical data, including topography, vegetation and soils, and underlying causal factors such as climate, geology and geomorphology. It was argued that:

This information had to be collated and mapped at a scale that was both appropriate for spatial description of agricultural, pastoral and settlement potential and relevant to the needs of policy-makers. The report also needed to identify priority areas and possible approaches to development of the area's land resources. (CSIRO Publishing, n.d.)

The resultant composite mapping unit was named the 'land system'; this was defined as 'an area or group of areas throughout which there is a recurring pattern of topography, soils, and vegetation' (Christian \& Stewart, 1952). This approach relied on the mapping of landscape patterns that could be identified from aerial photography or photo-mosaics supported by topographic and thematic maps, reports, fieldwork and expert knowledge. Aided by WWII-perfected stereoscopic aerial interpretation techniques, the continental coverage of vertical aerial photographs greatly facilitated this land research mapping initiative. 
The late 1960s saw another CSIRO division (soil mechanics) develop a further specific application of terrain evaluation. This initiative also utilised stereoscopic aerial photograph interpretation techniques. This system of terrain evaluation was known as the 'PUCE' (Pattern-UnitComponent-Evaluation) program. It was based on the acknowledgement and recognition that four parameters defined an area: the underlying geology, slope, soil and vegetation characteristics. The PUCE program provided a reliable and rapid method of evaluating the landscape in terms of its recurring composite patterns, units and components. As in the case of the early Land Research Series, the new initiative, known as Terrain Evaluation for Engineering Purposes, sought to 'provide rational formalized systems for ... planning, engineering works on a regional basis' (Grant, 1971, p. 81). By the late 1970s, large regional areas of northern and Central Australia had been mapped, as well as the principal metropolitan regions of Brisbane, Sydney, Melbourne and Perth and the nominated growth area of Albury-Wodonga.

\section{Post-WWII Planning (1946-50s)}

The post-WWII era witnessed the delineation of reconstruction regions that were to involve large national-scale initiatives to 'secure a peace time economy of full employment ... [in which] housing and town planning were seen as crucial to raising living standards' (Freestone, 2012, p. 1). This initiative was overseen by the Australian Government's Department of Post-War Reconstruction (1942-50). It was noted that some relevant recurrent themes included the importance of a multidisciplinary approach across physical, economic and social ends; coordination across all three levels of government; treating the urban environment holistically; and research-based evidence and scientific values. Citing H. C. Coombs, an influential bureaucrat of this era, Freestone observed that the Department of Post-War Reconstruction was 'concerned with the physical aspects of planning and development strategy as a countervailing force to dependence on purely financial instruments of resource allocation' (p. 4). However, these national-scale planning proposals took a back seat with the realisation that it was the states that had constitutional responsibility for physical land use planning, and that many of these proposals could be viewed as federal intrusion into state matters. 
In parallel with this (largely non-spatial) post-WWII reconstruction planning, a number of metropolitan- and regional-scale planning projects initiated by state and local government emerged, including the City of Brisbane Draft Town Planning Scheme (1944); the County of Cumberland Planning Scheme, encompassing the Greater Sydney region (1948); and the Melbourne Metropolitan Planning Scheme (1954). A close examination of these and other regional land use planning initiatives reveals no connection between them and the methodological approach of the environmental (landscape) resource mapping initiatives pioneered by CSIRO in the post-WWII era. There appears to have been limited detailed analysis of the biophysical aspects, especially the constraints and opportunities provided by those environmental attributes for future urban development. If the biophysical elements were considered, they were treated separately and were not seen as part of a holistic landscape unit.

\section{Planning for the 1960s and 1970s}

Planning for the next two decades of regional-scale land use endeavours witnessed the intensification of resource mapping and planning from time to time by various state and national governments. Of particular note at the national level were the Whitlam Labor Government's Growth Centres and New Cities planning initiatives. These bold urban and regional planning forays into hitherto state-dominated affairs saw joint federalstate nominations of growth centres, accompanied by a promise of federal funding subsequent to the preparation of land use plans that met Australian and state government objectives. Some of the major growth centres included Gosford-Wyong (NSW), Bathurst-Orange (NSW), Albury-Wodonga (NSW-Victoria), Monarto (SA), Darwin New Town (NT) and the Moreton Region (QLD). In subsequent years, the Australian Government's interest in metropolitan and regional land use planning waxed and waned, with inertia being the dominant characteristic. Meanwhile, most state governments completed various metropolitanand regional-scale strategic plans during this period of modest growth; an exception was the Brisbane City Council, the country's largest single metropolitan local authority, which completed its own plan. 


\section{Lost Opportunities}

There were numerous attempts to plan at the regional- and metropolitanscale throughout the post-WWII period, and these continued into the 1960s and 1970s. These initiatives, which involved all levels of government, were of a strategic planning nature that sought to satisfy a number of similar objectives, including the identification of areas for future growth and the future form of cities and regions, and the assignment of broad land use allocations across the landscapes in question. It could be assumed that these broad strategic planning objectives were informed by a detailed understanding of the biophysical attributes of the respective planning areas. Further, it could be assumed that these physical planning endeavours might have accessed existing environmental (landscape) resource mapping initiatives of the type undertaken by CSIRO. Yet this did not always occur, and it is puzzling as to why planners did not employ similar methodological approaches to inform their planning process. The question of an assumed association between early land resource studies and regional and metropolitan land use planning initiatives is even more relevant when it is noted that the former were more than just natural resource inventories - in many cases, they involved assessments of the physical attributes of the landscape to accommodate various forms of urban and infrastructure development. For example, the CSIRO division of soil mechanics' PUCE Terrain Evaluation for Engineering Purposes series covered several metropolitan regions, including Brisbane, Sydney, Melbourne and Perth. However, there is little evidence that the various land use planning initiatives were informed by these resource mapping initiatives, or hybrids based on their methodology. If they were, then other-non-environmental—considerations overrode the environmental (biophysical) values in the final land use planning process; this is what occurs in political decision-making processes.

The classic case in point is the tragic loss of the highly valuable krasnozems and red earth soils that formerly dominated elevated locations on the fringe of Brisbane city. These areas supported productive market gardens; however, they were also sought after for 'greenfield' land development due to their elevated locations, proximity to Brisbane and location within the commuting zone of increasingly affluent city workers. The ability of the land development industry to outbid farming interest in the purchase of these areas was also a factor. Hence, in the planning processes for these areas, economic values and the interests of land developers took 
precedence over biophysical-landscape values and agricultural interests, and these productive fruit- and vegetable-growing areas were lost forever. This situation has been repeated in many other sprawling urban centres. While the question of environmental (landscape) values is complex (particularly their place in the even more complex planning and policy decision-making process), it is contended that consideration of the biophysical attributes of the landscape should have played a greater role in the planning process.

Putting aside the political processes, the apparent lack of a nexus between land use planning and environmental resource studies raises a number of questions:

1. Were the planners of this era aware of these various examples of technical environmental-landscape data upon which sound land use planning decisions should have been made?

2. If they were, why didn't they access such input or commission such studies?

3. Were land use planners capable of interpreting this data and incorporating it into their land use planning processes?

\section{Challenges of Traditional Land Use Planning}

In reviews of attempts to address past environmental and development challenges through planning, several shortcomings of traditional land use planning have been noted. Although it can embrace a broad range of planning endeavours, for the most part, traditional land use planning education and practice has been (and continues to be) almost exclusively associated with the design professions, such as architecture (i.e. it does not have strong environmental-biophysical underpinnings). Critics of the theory and practice of traditional forms of planning have noted the following shortcomings:

- physical and design bias (Taylor, 1998)

- normative approach that overemphasises utopian ideals; conservative concern for aesthetics; promotes a 'technicalist' view of planning (Taylor, 1998)

- singular urban and economic efficiency concentration (Herring, 1999) and lack of rural focus (Laut \& Taplin, 1988) 
- underpinned by laws, regulations and guidelines that were developed to protect society from human error, and for health, safety and welfare reasons, rather than environmental sustainability (Forman, 1995)

- lack of a suitable philosophical perspective to address emergent environmental management and ecological issues (Conacher \& Conacher, 2000)

- lack of adequate science input (Johnson, Swanson, Herring \& Greene, 1999).

Consistent with these shortcomings, one critic observed that:

Strategic planning needs to be based on a better understanding of local and regional physical, social and economic environments in Australia's coastal zone, and this information must provide the basis for planning and managing of development. (Graham, cited in Resource Assessment Commission, 1993, p. 96)

On the question of whether planners were 'capable of interpreting that data and incorporating it into the land use planning process', it was noted that there was a 'lack of information and poor communication channels between scientists and managers' (House of Representatives Standing Committee on Environment Recreation and the Arts, 1991, p. 42). Opdam, Foppen and Vos (2002) also acknowledged the lack of a nexus. However, they saw the challenge from the opposite perspective, pointing out that:

Most empirical process studies are of no use to landscape management as long as we fail to transfer the information to the level of problem solving ... [We must ensure] that this gap between process studies and spatial planning is bridged ... [The] lack of a mechanistic basis for a holistic landscape ecology and, consequently, for spatial planning, is because many empirical and theoretical ecological studies fail to transfer their results in the context of landscape pattern. (pp. 767-68)

As landscape managers, land use planners need to appreciate the value of biophysical information in their planning decisions; they need to be aware of the existence of this data; they need to be able to commission similar natural resource (landscape) studies; and, importantly, they need to be able to interpret biophysical scientific data for planning purposes. 


\section{An Alternative Planning Paradigm (1970s and 1980s)}

While not an entirely new paradigm, the landscape (ecological) planning approach was given renewed emphasis from the early 1970s with the publication of Ian McHarg's (1969) seminal work Design with Nature. McHarg wrote:

We need nature as much in the city as in the countryside. In order to endure we must maintain the bounty of that great cornucopia which is our inheritance. It is clear that we must look deep to the values which we hold ... these must be transformed ... to do this [we] must design with nature. (p. 5)

McHarg's advocacy coincided with the Whitlam Government's Growth Centres planning initiative that, as noted, rarely connected the land use planning function with scientific landscape assessments that were capable of informing the planning process. The same was true of background studies used to support the raft of other (largely stateinitiated) regional- and metropolitan-scale planning studies of this era. Although a number of state-based systems did adopt, or modify, CSIRO's land resource methodology, these were mostly agencies that had strict conservation planning functions for state lands only (e.g. the Victorian Land Conservation Council [now Victorian Environmental Assessment Council]) or had no mainstream land use planning function in relation to land development (e.g. Department of Primary Industries). Reflecting on lost opportunities, when Design with Nature was republished in 1992, McHarg observed that:

In 1969, while many people accepted the proposition-Design with Nature-there was no legislation empowering or requiring ecological planning ... now the situation is vastly different and it is the new legislation which provides this [new] book with an enlarged purpose ... the power to employ ecological planning from national to local scales has accumulated slowly. Serious omissions remain, notably the fragmentation of environmental sciences and the plethora of responsible institutions, but there are now innumerable opportunities to employ the method. (1992, p. vi) 


\section{Contemporary Planning (1990s-present)}

McHarg's observation sums up the current regional planning situation in Queensland. The South East Queensland (SEQ) region, which contains the state capital of Brisbane city, has experienced phenomenal population growth by Australian standards over the last decade and is expected to remain the fastest growing metropolitan region in the country for at least the next decade. Strategic regional planning for SEQ has been completed under the auspices of Queensland's Sustainable Planning Act 2009 (as amended), which, like almost all state and territory planning legislation, is underpinned by the principles of ecologically sustainable development. Sustainable development aims to provide for the social and economic needs of society, while protecting environmental resources and values for the future (World Commission on Environment and Development, 1987).

Featuring 'values-led' planning, this paradigm advocates for an evidencebased approach that leads to science informing both planning and the values upon which planning is predicated. In an environmental context, values have been defined as 'direct and indirect qualities of natural systems that are important to the evaluator' (Satterfield, 2001, p. 332). Contemporary planning processes and practices can facilitate a valuesled approach, whereby the vision and aspirational statements that guide and direct the plan attest to the collective values of those communities engaged through the planning process.

Low Choy (2015) showed how the values of communities that seek a high degree of liveability are associated with planning processes that ensure that key landscape attributes (i.e. attributes that have a positive influence on the achievement of the aspirational vision of liveability) are protected. This relationship between community (environmental) values and the achievement of community aspirations of liveability through the protection of key landscape attributes is illustrated graphically in Figure 5.1.

Values-led planning acknowledges that planning operates within a political and often highly contested context, which invariably involves contestations about the different values that sections of a community hold. Planning should be led by contemporary values, and these should be elicited through appropriate community engagement processes that are informed by robust evidence, including the best available science. In this way, regional-scale strategic land use planning can incorporate 
landscape values that have been informed by science that is consistent with biophysical (landscape) data, as exemplified by the environmental (landscape) reports of the post-WWII resource mapping initiatives (see Queensland Government, 2009).

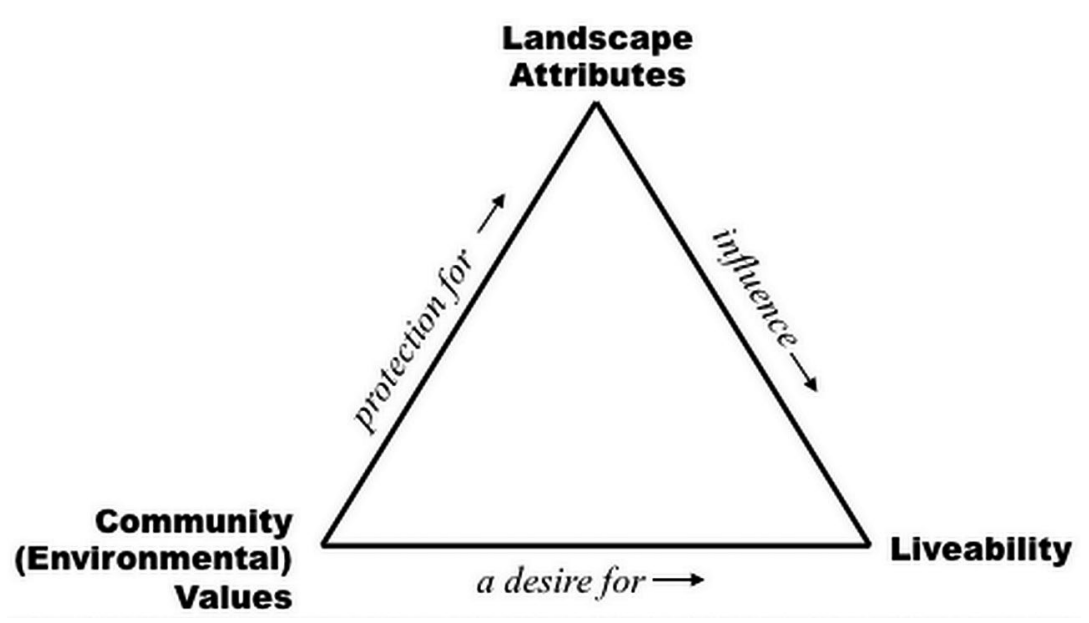

Figure 5.1: Relationship between landscapes, values and a community goal of liveability.

Source: Low Choy (2015).

\section{Recommendations}

Conventional land use planners are not trained as scientists; they do not come from a scientific background and many have limited experience in dealing with scientists. Further, scientists have not traditionally collaborated with land use planners. Science-informed planning paradigms were very rarely advanced in the past; however, there have been attempts to seek robust and sustainable outcomes in recent years, as exemplified by numerous contemporary metropolitan planning schemes. Enhancing the nexus between planning and science needs to be addressed, in the first instance, through education. Both disciplines need to be modified and this will take time. In the meantime, the following strategic principles for integrating science and planning will go some way towards strengthening the nexus:

- incorporate scientific analysis and review throughout the entire planning process

- integrate scientists and their work into the planning process from the beginning 
- respect scientific independence: scientists must remain objective

- planners must clarify the specific type and scale of scientific expertise and information required for the planning initiative in question

- scientists must provide their work in 'user-friendly' formats

- planners must put forward credible technical solutions, based on best available science, to have the greatest chance in competing against other interests in the political decision-making process.

These initiatives will succeed if they are implemented under the auspices of overarching planning reform at national and state levels. At the national scale, an opportunity for the future has been advanced by the Wentworth Group of Concerned Scientists (2014), an independent group of Australian scientists, economists and business people concerned with advancing solutions to secure the long-term health of Australia's land, water and biodiversity. In November 2014, the Wentworth Group released their 'Blueprint for a Healthy Environment and a Productive Economy'. In this national-level response to contemporary land, water and biodiversity challenges, the Wentworth Group advanced five transformative, long-term economic and institutional reforms-two of which are relevant to this chapter:

1. Fix land and water use planning:

We must put in place regional scale land and water use plans that address the cumulative impacts of development on the environment and the long-term costs to the economy.

\section{Regionalise management:}

We must embed and give prominence to natural resource management at the regional scale to reconnect people to the land, so that investment decisions are underpinned by an understanding of how landscapes function. (p. 2)

Ideally, future land use planners will better appreciate the valuable role that science (especially biophysical science) can have in informing the planning process, and they will be capable of accessing and utilising scientific input into their planning endeavours. This, in turn, will lead to more robust and politically argued outcomes. The future should also witness a reciprocal understanding between planners and scientists, in which scientists freely engage with planners, communicating their 
science in ways that planners can use for planning purposes. Holistic and environmentally based planning, with a strong nexus between land use planning and environmental sciences, will require a 'marriage' between planners and scientists. As the past has shown with respect to traditional land use planners, this necessitates a concerted effort to understanding that 'you don't know what you don't know'.

\section{References}

Christian, C. S. \& Stewart, G. A. (1952). A survey of the KatherineDarwin region, 1946. Land Research Series: No 1. Canberra, ACT: CSIRO Publishing.

Conacher, A. \& Conacher, J. (2000). Environmental planning and management in Australia. Melbourne, VIC: Oxford University Press.

CSIRO Publishing. (n.d.). CSIRO land research surveys: Mapping land resources in Australia and Papua New Guinea. Retrieved from www.publish.csiro.au/nid/289.htm

Freestone, R. (2012). Post-war reconstruction and planning promotion in 1940s Australia. Paper presented at the 15th International Planning History Society Conference, Sao Paulo, Brazil, July 2012.

Forman, R. T. T. (1995). Land mosaics—the ecology of landscapes and regions. Cambridge, UK: Cambridge University Press.

Grant, K. (1971). Terrain evaluation for engineering purposes. In Proceedings of symposium on terrain evaluation for highway engineering, special report no 6 (pp. 81-107). Melbourne, VIC, Australian Road Research Board.

Herring, M. (1999). Introduction. In K. N. Johnson, F. J. Swanson, M. Herring \& S. Greene (Eds.), Bioregional assessments-science at the crossroads of management and policy. Washington DC: Island Press. doi.org/10.1002/j.2164-490x.1999.tb00063.x

House of Representatives Standing Committee on Environment Recreation and the Arts. (1991). The injured coastline: Protection of the coastal environment. Canberra, ACT: Australian Government Publishing Service. 
Johnson, K. N., Swanson, F. J., Herring, M. \& Greene, S. (Eds.). (1999). Bioregional assessments—science at the crossroads of management and policy. Washington, DC: Island Press.

Laut, P. \& Taplin, B. J. (1988). Catchment management in Australia in the 1980s. Canberra, ACT: Division of Water Resources, CSIRO.

Low Choy, D. C. (2015). Managing ecosystem services in the peri-urban landscape: An emergent paradox. Paper presented at the Second International Conference on Agriculture in an Urbanizing Society, Italy, September 2015.

McHarg, I. L. (1969). Design with nature. New York, NY: Doubleday/ Natural History Press.

McHarg, I. L. (1992). Design with nature. New York, NY: John Wiley.

Opdam, P., Foppen, R. \& Vos, C. (2002). Bridging the gap between ecology and spatial planning in landscape ecology. Landscape Ecology 16, 767-79. doi.org/10.1023/A:1014475908949

Queensland Government. (2009). South East Queensland regional plan 2009-2031. Brisbane, QLD: Department of Infrastructure and Planning.

Resource Assessment Commission. (1993). Resource Assessment Commission coastal zone inquiry: Final report. Canberra, ACT: Australian Government Publishing Service.

Satterfield, T. (2001). In search of value literacy: Suggestions for the elicitation of environmental values. Environmental Values 10(3), 331-59. doi.org/10.3197/096327101129340868

Taylor, N. (1998). Urban planning theory since 1945. London, UK: Sage Publications.

Wentworth Group of Concerned Scientists. (2014). Blueprint for a healthy environment and a productive economy. Retrieved from wentworth group.org/wp-content/uploads/2014/11/Blueprint-for-a-HealthyEnvironment-and-a-Productive-Economy-November-2014.pdf

World Commission on Environment and Development. (1987). Our common future. New York, NY: Oxford University Press. 
This text is taken from Land Use in Australia: Past, Present and Future, edited by Richard Thackway, published 2018 by ANU eView, The Australian National University, Canberra, Australia.

doi.org/10.22459/LUA.02.2018.05 